\title{
Patient considerations and clinical utility of a fixed dose combination of saxagliptin/metformin in the treatment of type 2 diabetes
}

This article was published in the following Dove Press journal:

Diabetes, Metabolic Syndrome and Obesity:Targets and Therapy 29 June 2011

Number of times this article has been viewed

\author{
Giuseppe Derosa \\ Pamela Maffioli \\ Department of Internal Medicine \\ and Therapeutics, University of Pavia, \\ Pavia, Italy
}

Introduction: Targeting glycated hemoglobin $\left(\mathrm{HbA}_{1 \mathrm{c}}\right)$ levels below $7.0 \%$ is considered a primary goal of diabetes care, given its importance in obtaining a sustained reduction in microvascular, and possibly macrovascular complications.

Aim: The aim of this review was to evaluate the clinical utility of a fixed dose combination of saxagliptin/metformin in the treatment of type 2 diabetes.

Evidence review: The combination of saxagliptin/metformin was well tolerated and produced sustained glycemic control for up to 76 weeks, with greater improvements in glycemic parameters compared with either drug alone. The saxagliptin/metformin combination also proved its non-inferiority compared with either sulfonylurea/metformin or sitagliptin/metformin combinations.

Place in therapy: Clinical practice recommends lifestyle interventions together with starting metformin at the time that the type 2 diabetes mellitus is diagnosed. Once metformin fails to maintain glycemic control, the addition of DPP-4 inhibitors should be the logical choice because of their effects on $\mathrm{HbA}_{1 \mathrm{c}}$ compared to the addition of a sulfonylurea or glitazone, and because of their positive effects on beta cell function and their neutral effects on body weight. Furthermore, DPP-4 inhibitors prevent the risk of hypoglycemia posed by sulfonylureas.

Keywords: DPP-4 inhibitors, saxagliptin, glycemic control, insulin sensitivity, HOMA index

\section{Introduction}

Targeting glycated hemoglobin $\left(\mathrm{HbA}_{1 \mathrm{c}}\right)$ levels below $7.0 \%$ is considered a primary goal of diabetes care, given its importance in obtaining a sustained reduction in microvascular, and possibly macrovascular complications. ${ }^{1}$ However, maintaining adequate metabolic control is still a challenge in many patients with type 2 diabetes mellitus (T2DM). ${ }^{2}$ Current guidelines from the American Diabetes Association/European Association for the Study of Diabetes (ADA/EASD) and American Association of Clinical Endocrinologists/American College of Endocrinology (AACE/ACE) recommend early initiation of combination therapy with oral antidiabetic drugs in patients with $\mathrm{HbA}_{1 \mathrm{c}}>8.5 \%$ and $7.6 \%-9.0 \%$, respectively. ${ }^{1,3}$ In particular metformin is recommended (unless specifically contraindicated) as a first-line agent for monotherapy and combination therapy for patients with T2DM. This recommendation is based primarily on metformin's glucose-lowering effects, absence of weight gain, generally low level of side effects, and relatively low cost. ${ }^{1,3}$

While monotherapy with oral antidiabetic drugs may be effective in improving glycemic control in the short term, dose adjustments or combination therapy are often
Department of Internal Medicine and

Therapeutics, University of Pavia,

Fondazione IRCCS Policlinico S. Matteo

P.le C. Golgi, 2-27I00 Pavia, Italy

Tel $+39-0382526217$

Fax +39-0382 526259

Email giuseppe.derosa@unipv.it 
required for long-term control because of the progressive loss of $\beta$-cell function and increase in insulin resistance. ${ }^{4}$ In this regard, recent breakthroughs in the understanding of incretin-based therapies have provided additional options for the treatment of T2DM. Incretins are gastrointestinal hormones released during nutrient absorption to increase insulin secretion. The two gut peptides accounting for most of the incretin effect are glucagon-like peptide 1 (GLP-1) and glucose-dependent insulinotropic peptide (GIP). In response to a meal, GLP-1 and GIP are released and, in turn, stimulate insulin (both in a glucose-dependent manner), delay gastric emptying, and increase satiety. ${ }^{5,6}$ Furthermore, GLP-1 acts on alpha cells and inhibits the secretion of glucagons. ${ }^{7}$ Within some minutes of release from their intestinal sites, GIP and GLP-1 undergo rapid metabolism (proteolytic cleavage) to inactive metabolites by the enzyme dipeptidyl peptidase-4 (DPP-4). In T2DM, GLP-1 concentrations are reduced in response to a meal, whereas GIP concentrations are normal or increased. This observation suggests resistance to the action of GIP, making GLP-1 the favored potential therapeutic target. ${ }^{8}$

Because GLP-1 is rapidly degraded by DPP- $4,{ }^{9}$ a new class of compounds have been developed: DPP-4 inhibitors, that delay endogenous degradation of GLP-1 and GIP. Inhibition of the proteolytic DPP-4 enzyme results in a two- to three-fold increase in circulating levels of GLP-1 and GIP, suppressing glucagon secretion in the post-prandial state, stimulating glucose dependent insulin secretion from pancreatic $\beta$-cells, ${ }^{10-12}$ and decreasing hepatic glucose production in the fasting state, thereby reducing both fasting plasma glucose (FPG) and post-prandial glucose (PPG). ${ }^{4,13}$ The first DPP-4 inhibitor released for use in clinical practice was sitagliptin, followed by vildagliptin and saxagliptin. Sitagliptin received US Food and Drug Administration approval in October 2006 and received European Medicines Agency approval in March 2007. It is licensed at the recommended dose of $100 \mathrm{mg}$ once daily either as monotherapy or in combination. As monotherapy, the indication in the US is as an adjunct to diet and exercise to improve glycemic control in patients with T2DM, whereas in the EU, sitagliptin is indicated as monotherapy in patients who have inadequate glycemic control with diet and exercise and in whom metformin is inappropriate due to contraindications or intolerance. Sitagliptin is also indicated, both in the US and in EU, in combination therapy with metformin, a sulfonylurea, or a thiazolidinedione in patients who have inadequate control with these agents used as single agents plus diet and exercise. Recently, sitagliptin was also approved to be used in combination with insulin. Sitagliptin is also indicated as a triple therapy in combination with metformin plus a sulfonylurea, or metformin plus a thiazolidinedione, in patients who have inadequate glycemic control with the two agents (Table 1). ${ }^{14}$ Vildagliptin was approved by the European Medicines Agency in July 2007 and it is licensed at the recommended dose of $50 \mathrm{mg}$ twice a day in combination with either metformin or sulfonylureas or thiazolidinediones in patients poorly controlled on the maximum doses of these drugs (Table 1). ${ }^{15}$ Saxagliptin, the last addition to the family of DPP-4 inhibitors, is administered at the recommended dose of $5 \mathrm{mg}$ once daily in combination with metformin, or sulfonylureas or a thiazolidinedione (Table 1). ${ }^{15}$ The mechanism of action of the DPP-4 inhibitors is complementary to that of metformin, which improves insulin sensitivity and reduces hepatic glucose production, ${ }^{12}$ for this reason this combination can be very useful in the clinical practice, to achieve an adequate glycemic control. The aim of this review was to evaluate the clinical utility of a fixed dose combination of saxagliptin/metformin in the treatment of type 2 diabetes.

\section{Material and methods}

A systematic search strategy was developed to identify randomized controlled trials in both MEDLINE (National Library of Medicine, Bethesda, MD; 1996 through March 2011) and the Cochrane Register of Controlled Trials (The Cochrane Collaboration, Oxford, United Kingdom). The terms "DPP-4 inhibitors", "saxagliptin", "metformin", "combination saxagliptin/metformin", "fixed dose of saxagliptin/metformin" were incorporated into an electronic search strategy that included the Dickersin filter for randomized controlled trials. ${ }^{16}$ It was also discovered that some reports have only been published in languages other than English. To avoid problems and limitations with the translation of these reports, it was decided to perform this review by including only studies published in English. The bibliographies of all identified randomized trials and review articles were reviewed to look for additional studies of interest. We subsequently reviewed the potential trials to determine their eligibility. To qualify for inclusion, clinical trials were required to be randomized trials comparing a fixed dose of saxagliptin/metformin combination with any other oral antidiabetic drug in type 2 diabetic patients. Eligible trials had to present results on glycemic control, insulin resistance, insulin sensitivity and adverse events. Two different outcomes related to glycemic control improvement were of primary interest: (1) the proportion of individuals within each treatment group achieving clinically significant 
Table I DPP-4 agonists: dosage and use

\begin{tabular}{|c|c|c|}
\hline Drug & Dosage & Use \\
\hline Sitagliptin & 100 mg once daily & $\begin{array}{l}\text { As an adjunct to diet and exercise to improve glycemic control as an add-on therapy to: } \\
\text { - metformin (dual therapy) } \\
\text { - sulfonylurea (dual therapy) } \\
\text { - pioglitazone (dual therapy) } \\
\text { - sulfonylurea plus metformin (triple therapy) } \\
\text { - pioglitazone plus metformin (triple therapy) } \\
\text { - In the US as monotherapy; in the EU as monotherapy in patients in whom metformin is } \\
\text { inappropriate due to contraindications or intolerance } \\
\text { - Insulin (with or without metformin) }\end{array}$ \\
\hline Vildagliptin & 50 mg twice daily & $\begin{array}{l}\text { As an adjunct to diet and exercise to improve glycemic control as an add-on therapy to: } \\
\text { - metformin (dual therapy) } \\
\text { - sulfonylurea (dual therapy): in that case vildagliptin should be used at the dosage of } 50 \mathrm{mg} / \text { day } \\
\text { - pioglitazone (dual therapy) }\end{array}$ \\
\hline Saxagliptin & 5 mg once daily & $\begin{array}{l}\text { As an adjunct to diet and exercise to improve glycemic control as an add-on therapy to: } \\
\text { - metformin (dual therapy) } \\
\text { - sulfonylurea (dual therapy) } \\
\text { - pioglitazone (dual therapy) }\end{array}$ \\
\hline
\end{tabular}

$\mathrm{HbA}_{1 \mathrm{c}}$ reduction, and (2) the mean amount decrease (in\%) within each treatment group. Variations in insulin resistance and insulin sensitivity that occurred during various trials were secondary outcomes of interest, as was the frequency of patients having one or more adverse events such as hypoglycemia. A validated, 3-item scale was used to evaluate the overall reporting quality of the trials selected for inclusion in the present review. This scale provided scoring for randomization ( $0-2$ points), double-blinding ( $0-2$ points), and account for withdrawals ( 1 point). Scores ranged between 0 and 5. A score above 3 indicated a study of high quality and study selection was restricted to randomized controlled trials to ensure the inclusion of only high quality evidence. ${ }^{17}$

\section{Chemical structure, including key PK/PD data}

Saxagliptin (BMS-477118; (S)-3 hydroxyadamantylglycineL-cis-4,5 methanoprolinenitrile) is a nitrile-containing DPP-4 inhibitor, with the molecular formula $\mathrm{C}_{18} \mathrm{H}_{27} \mathrm{~N}_{3} \mathrm{O}_{3}$ and a molecular weight of $333.4 \mathrm{Da}$. It is a potent inhibitor of DPP-4 (inhibition constant, $\mathrm{Ki}=0.6-1.3 \mathrm{nM}$ ) that displays slow-binding properties. Thus, kinetic studies have suggested that inhibition of DPP-4 by saxagliptin is a twostep process that involves formation of a reversible covalent enzyme inhibitor complex, in which there is a slow onset of inhibition and a slow rate of inhibitor dissociation, resulting in the enzyme slowly equilibrating between the active and inactive forms. ${ }^{18,19}$ Metformin hydrochloride (N,N-dimethylimidodicarbonimidic diamide hydrochloride) is a white to off-white crystalline compound with a molecular formula of $\mathrm{C}_{4} \mathrm{H}_{11} \mathrm{~N}_{5} \mathrm{HCl}$ and a molecular weight of $165.63 \mathrm{Da}$. Metformin hydrochloride is freely soluble in water and is practically insoluble in acetone, ether, and chloroform. The $\mathrm{pKa}$ of metformin is 12.4 . The $\mathrm{pH}$ of a $1 \%$ aqueous solution of metformin hydrochloride is 6.68 .

\section{Efficacy studies with saxagliptin/ metformin}

For a summary of the following studies, see Table 2 .

\section{Saxagliptin/metformin as initial therapy}

Pfützner et al assessed the efficacy and safety of saxagliptin/metformin combination therapy compared with saxagliptin or metformin alone over 24 and 76 weeks in treatment-naive T2DM patients with inadequate glycemic control. ${ }^{20,21}$ One thousand, three hundred and six patients, 18-77 years of age $\left(\mathrm{HbA}_{1 \mathrm{c}} 8.0 \%-12.0 \%\right)$, were randomized to saxagliptin/metformin $5 / 500 \mathrm{mg}$, saxagliptin/metformin $10 / 500 \mathrm{mg}, 10 \mathrm{mg}$ saxagliptin/placebo or $500 \mathrm{mg}$ metformin/placebo. At week 76, adjusted mean changes $(95 \%$ CI) from baseline $\mathrm{HbA}_{1 \mathrm{c}}$ were $-2.31 \%(-2.44,-2.18)$ for saxagliptin/metformin 5/500 $\mathrm{mg},-2.33 \%(-2.46,-2.20)$ for saxagliptin/metformin 10/500 $\mathrm{mg},-1.55 \%(-1.70$, $-1.40)$ for saxagliptin $10 \mathrm{mg}$ and $-1.79 \%(-1.93,-1.65)$ for metformin $500 \mathrm{mg}(P<0.0001$ versus metformin and saxagliptin monotherapies for saxagliptin/metformin $5 / 500 \mathrm{mg}$ and saxagliptin/metformin $10 / 500 \mathrm{mg}$ ). A higher proportion of patients achieved a $\mathrm{HbA}_{1 \mathrm{c}}<7 \%$ at week 76 with saxagliptin/metformin 5/500 $\mathrm{mg}$ and saxagliptin/metformin 
Table 2 summary of the studies included in the review

\begin{tabular}{|c|c|c|c|c|}
\hline Study & Duration & Drugs involved & Baseline population & Results \\
\hline \multirow[t]{4}{*}{ Pfützner et $\mathrm{al}^{20,21}$} & 76 weeks & - saxagliptin/metformin 5/500 mg & $\begin{array}{l}\text { I } 306 \text { patients, I8-77 years of } \\
\text { age with } \mathrm{HbA}_{\mathrm{Ic}} 8.0 \%-12.0 \% \text {. }\end{array}$ & $\begin{array}{l}\text { HbA }_{\mathrm{Ic}}: \\
\bullet-2.3 \mathrm{I} \% \text { for saxagliptin/metformin } \\
5 / 500 \mathrm{mg} *\end{array}$ \\
\hline & & - saxagliptin/metformin 10/500 mg & & $\begin{array}{l}-2.33 \% \text { for saxagliptin/metformin } \\
10 / 500 \mathrm{mg} *\end{array}$ \\
\hline & & - saxagliptin $10 \mathrm{~g} /$ placebo & & $\bullet-1.55 \%$ for saxagliptin $10 \mathrm{mg}$ \\
\hline & & - metformin 500 mg/placebo. & & $\begin{array}{l}\bullet-1.79 \% \text { for metformin } 500 \mathrm{mg} \\
(* P<0.000 \mathrm{I} \text { versus metformin } \\
\text { and saxagliptin monotherapies })\end{array}$ \\
\hline \multirow[t]{3}{*}{ Scheen et $\mathrm{al}^{22}$} & 18 weeks & & $80 \mathrm{I}$ patients with $\mathrm{HbA}_{\mathrm{Ic}}$ between & $\mathrm{HbA}_{\mathrm{Ic}}:$ \\
\hline & & $\begin{array}{l}\text { - saxagliptin } 5 \text { mg once daily } \\
\text { as add on therapy to } \\
\text { previously taken metformin }\end{array}$ & $\begin{array}{l}6.5 \%-10 \% \text { on stable metformin } \\
\text { doses }(1500-3000 \mathrm{mg} / \text { day })\end{array}$ & $\bullet-0.52 \%$ for saxagliptin/metformin \\
\hline & & $\begin{array}{l}\text { - sitagliptin } 100 \mathrm{mg} \text { once daily } \\
\text { as add-on therapy to previously } \\
\text { taken metformin. }\end{array}$ & & $\begin{array}{l}-0.62 \% \text { for sitagliptin/metformin } \\
(P \text { not significant })\end{array}$ \\
\hline \multirow[t]{9}{*}{ De Fronzo et $\mathrm{a}^{23}$} & 24 weeks & & 743 patients taking a stable dose & $\mathrm{HbA}_{\mathrm{Ic}}:$ \\
\hline & & - saxagliptin 2.5 mg once daily & of metformin ( 1.500 but & - $-0.59 \%$ for saxagliptin \\
\hline & & $\begin{array}{l}\text { as add on therapy to previously } \\
\text { taken metformin }\end{array}$ & not $>2.550 \mathrm{mg} /$ day) & $2.5 \mathrm{mg} / \mathrm{metformin} *$ \\
\hline & & - saxagliptin 5 mg once daily & & - $-0.69 \%$ for saxagliptin \\
\hline & & $\begin{array}{l}\text { as add on therapy to previously } \\
\text { taken metformin }\end{array}$ & & $5 \mathrm{mg} /$ metformin* \\
\hline & & - saxagliptin 10 mg once daily & & - $-0.58 \%$ for saxagliptin \\
\hline & & as add on therapy to previously & & 10 mg/metformin* \\
\hline & & taken metformin & & \\
\hline & & $\begin{array}{l}\text { - placebo as add on therapy } \\
\text { to previously taken metformin. }\end{array}$ & & $\begin{array}{l}\bullet+0.13 \% \text { for placebo/metformin } \\
(* P \leq 0.000 \text { I versus placebo })\end{array}$ \\
\hline \multirow[t]{11}{*}{ Goke et $\mathrm{a}^{24}$} & 52 weeks & & 858 patients on stable metformin & $\mathrm{HbA}_{\mathrm{Ic}}:$ \\
\hline & & $\begin{array}{l}\text { - saxagliptin } 5 \mathrm{mg} \text { once daily } \\
\text { as add on therapy to previously } \\
\text { taken metformin }\end{array}$ & doses $\geq 1500 \mathrm{mg} /$ day & $\bullet-0.74 \%$ for saxagliptin/metformin \\
\hline & & - glipizide up-titrated as needed & & • $-0.80 \%$ for glipizide/metformin \\
\hline & & from 5 to $20 \mathrm{mg} /$ day as add & & (P not significant) \\
\hline & & on therapy to previously & & \\
\hline & & & & Hypoglycemia: \\
\hline & & & & - $3 \%$ for saxagliptin/metformin* \\
\hline & & & & $\begin{array}{l}\cdot 36.3 \% \text { for glipizide/metformin } \\
(* P<0.0001 \text { versus glipizide/metformin })\end{array}$ \\
\hline & & & & Body weight: \\
\hline & & & & - -I.I kg for saxagliptin/metformin* \\
\hline & & & & $\begin{array}{l}\cdot+1.1 \mathrm{~kg} \text { for with glipizide/metformin } \\
\left({ }^{* P}<0.0001 \text { versus glipizide/metformin }\right)\end{array}$ \\
\hline
\end{tabular}

10/500 mg than with either agent alone. Similarly, a higher proportion of patients achieved a $\mathrm{HbA}_{1 \mathrm{c}}<6.5 \%$ at week 76 with saxagliptin/metformin 5/500 mg and saxagliptin/metformin 10/500 $\mathrm{mg}$ than with either agent alone. For FPG at week 76, saxagliptin/metformin 5/500 mg and saxagliptin/ metformin 10/500 $\mathrm{mg}$ groups had similar results $(-54 \pm 2.6$ and $-55 \pm 2.6 \mathrm{mg} / \mathrm{dL}$, respectively), while changes for the monotherapy groups were smaller $(-24 \pm 3.0 \mathrm{mg} / \mathrm{dL}$ for saxagliptin $10 \mathrm{mg}$ and $-40 \pm 2.8 \mathrm{mg} / \mathrm{dL}$ for metformin). For post-prandial glucose (PPG) at week 76, adjusted mean decrease from baseline was: $-137 \pm 5.6 \mathrm{mg} / \mathrm{dL}$ with saxagliptin/metformin 5/500 mg; $-129 \pm 5.9 \mathrm{mg} / \mathrm{dL}$ with saxagliptin/ metformin 10/500 mg; $-94 \pm 6.6 \mathrm{mg} / \mathrm{dL}$ with saxagliptin monotherapy; and $-86 \pm 5.9 \mathrm{mg} / \mathrm{dL}$ with metformin/ placebo. Changes with saxagliptin/metformin combination were greater than either monotherapy. Small decreases in 
mean body weight were observed in all treatment groups. The safety profile was similar across treatment groups: in particular the overall frequency of hypoglycemic events was low $(4.7 \%$ with saxagliptin/metformin $5 / 500 \mathrm{mg}, 6.8 \%$ with saxagliptin/metformin $10 / 500 \mathrm{mg}, 2.1 \%$ with saxagliptin $10 \mathrm{mg}$, and $6.1 \%$ with metformin alone).

\section{Saxagliptin as add-on therapy to metformin}

Scheen et al compared the efficacy of saxagliptin in combination with metformin compared with sitagliptin in combination with metformin in 801 patients with $\mathrm{HbA}_{1 \mathrm{c}}$ between $6.5 \%-10 \%$ on stable metformin doses (1500-3000 mg/day). ${ }^{22}$ Patients were randomized to add-on $5 \mathrm{mg}$ saxagliptin or $100 \mathrm{mg}$ sitagliptin once daily for 18 weeks. The addition of saxagliptin or sitagliptin to metformin therapy produced similar decreases in mean $\mathrm{HbA}_{1 \mathrm{c}}$ from baseline to week 18. Mean $\mathrm{HbA}_{1 \mathrm{c}}$ declined from 7.68 to $7.16 \%$ in the saxagliptin/metformin group; the adjusted mean $\pm \mathrm{SE}$ change was $-0.52 \% \pm 0.039$ (95\% CI, -0.60 to $-0.45 \%)$. Similarly, mean $\mathrm{HbA}_{1 \mathrm{c}}$ declined from 7.69 to $7.07 \%$ in the sitagliptin/metformin group, an adjusted mean change of $-0.62 \% \pm 0.038$ ( $95 \%$ CI, -0.69 to $-0.54 \%$ ). The proportion of patients achieving therapeutic glycemic responses was similar in the two treatment groups. Overall, 105 of 399 patients (26.3\%) who received saxagliptin/metformin compared with 114 of 392 patients (29.1\%) who received sitagliptin/ metformin achieved a $\mathrm{HbA}_{1 \mathrm{c}} \leq 6.5 \%$ at week 18. For those with a $\mathrm{HbA}_{1 \mathrm{c}} \geq 7.0 \%$ at baseline, 97 of 294 patients $(33.0 \%)$ in the saxagliptin/metformin group and 117 of 299 patients (39.1\%) in the sitagliptin/metformin group achieved a $\mathrm{HbA}_{1 \mathrm{c}}<7.0 \%$ at week 18 , a $-6.1 \%$ difference between groups ( $95 \% \mathrm{CI},-13.8$ to $1.6 \%$ ). Improvements in glycemic control were also observed as decreases in FPG from baseline to week 18. Adding saxagliptin or sitagliptin to metformin therapy produced adjusted mean changes in FPG of $-0.60 \mathrm{mmol} / \mathrm{L}(-10.8 \mathrm{mg} / \mathrm{dL})$ and $-0.90 \mathrm{mmol} / \mathrm{L}$ $(-16.2 \mathrm{mg} / \mathrm{dL})$, respectively. The mean difference was $0.30 \mathrm{mmol} / \mathrm{L}(5.42 \mathrm{mg} / \mathrm{dL}) ; 95 \% \mathrm{CI}, 0.08-0.53 \mathrm{mmol} / \mathrm{L}$ $(1.37-9.47 \mathrm{mg} / \mathrm{dL})$. There were no apparent differences between treatment groups for the changes from baseline in fasting insulin, glucagon, proinsulin, or C-peptide. Similarly, the small improvement in $\beta$-cell function, as measured by the change from baseline in homeostasis model assessment-2 $\beta$ (HOMA-2 $\beta$ ), did not differ between the two treatment groups. The safety profile of the two combinations was similar: in particular, hypoglycemic adverse events occurred in 13 patients (3.2\%) in the saxagliptin/metformin group and in 11 patients $(2.8 \%)$ in the sitagliptin/metformin group.

De Fronzo et $a^{23}$ evaluated the efficacy of combination of saxagliptin added to metformin compared to metformin alone in a 24-week randomized, double-blind, placebo-controlled trial. Seven hundred and forty three patients taking a stable dose of metformin (1.500 but not $>2.550 \mathrm{mg}$ / day) for at least 8 weeks before screening, were randomized to add $2.5,5$, or $10 \mathrm{mg}$ saxagliptin or placebo for 24 weeks in addition to their lead-in dose of open-label metformin. ${ }^{23}$ At week 24 , treatment with saxagliptin led to clinically and statistically significant reductions in $\mathrm{HbA}_{1 \mathrm{c}}$ from baseline versus metformin/ placebo. Differences in adjusted mean change from baseline versus placebo $(95 \% \mathrm{CI})$ were $-0.73 \%(-0.92$ to -0.53$)$ for the combination $2.5 \mathrm{mg}$ saxagliptin/metformin, $-0.83 \%(-1.02$ to -0.63 ) for the combination $5 \mathrm{mg}$ saxagliptin/metformin, and $-0.72 \%(-0.91$ to -0.52$)$ for the combination $10 \mathrm{mg}$ saxagliptin/metformin, respectively (all $P<0.0001$ ). Glycated hemoglobin reductions relative to metformin/placebo occurred in all saxagliptin treatment groups by week 4 , the earliest time point assessed. Maximal $\mathrm{HbA}_{1 \mathrm{c}}$ reductions were reached at 12 weeks and were sustained through 24 weeks. The percentage of patients achieving $\mathrm{HbA}_{1 \mathrm{c}}<7.0 \%$ was comparable for 5 and $10 \mathrm{mg}$ saxagliptin and higher than that for $2.5 \mathrm{mg}$ saxagliptin. A greater percentage of patients taking saxagliptin achieved $\mathrm{HbA}_{1 \mathrm{c}}<7.0 \%$ versus those taking metformin/placebo. The differences from metformin/placebo $(95 \% \mathrm{CI})$ were: $20.5 \%$ (10.6-30.5) for the combination $2.5 \mathrm{mg}$ saxagliptin/metformin; $27.0 \%(17.0-36.7)$ for the combination $5 \mathrm{mg}$ saxagliptin/ metformin; and $27.9 \%$ (17.7-37.7) for the combination $10 \mathrm{mg}$ saxagliptin/metformin, respectively (all $P<0.0001$ ). Statistically significant FPG reductions at week 24 were observed in all saxagliptin treatment groups versus the metformin/placebo group $(P<0.0001)$. Differences in adjusted mean change from baseline versus metformin/placebo $(95 \% \mathrm{CI})$ were:- $15.6 \mathrm{mg} /$ dL ( -22.5 to -8.5$)$ for the combination $2.5 \mathrm{mg}$ saxagliptin/ metformin; $-23.3 \mathrm{mg} / \mathrm{dL}(-30.3$ to -16.3$)$ for the combination $5 \mathrm{mg}$ saxagliptin/metformin; and $-21.7 \mathrm{mg} / \mathrm{dL}(-28.8$ to -14.7 ) for the combination $10 \mathrm{mg}$ saxagliptin/metformin, respectively. Differences between the effects of saxagliptin and metformin/placebo on mean FPG were apparent and near maximal as early as week 2 in all saxagliptin treatment groups, with the effect maintained throughout 24 weeks. The early insulin response based on the insulinogenic index, and insulin sensitivity, increased in all saxagliptin treatment groups at week 24. The overall frequency of confirmed hypoglycemia during the 24-week treatment period was similar for saxagliptin-treated 
patients $(0.5 \%)$ and metformin/placebo-treated patients $(0.6 \%)$. No dose relationship was observed among the three saxagliptin groups.

Goke et al assessed the efficacy and safety of saxagliptin compared to glipizide as add-on therapy to metformin in patients with type 2 diabetes mellitus and inadequate glycemic control on metformin alone. ${ }^{24} \mathrm{~A}$ total of 858 patients on stable metformin doses $\geq 1500 \mathrm{mg}$ /day were randomised to saxagliptin $5 \mathrm{mg} /$ day or glipizide up-titrated as needed from 5 to $20 \mathrm{mg} /$ day for 52 weeks. At 52 weeks, saxagliptin/ metformin was non-inferior to glipizide/metformin in lowering $\mathrm{HbA}_{1 \mathrm{c}}$. Adjusted mean changes from baseline $\mathrm{HbA}_{1 \mathrm{c}}$ were $-0.74 \%$ with saxagliptin/metformin and $-0.80 \%$ glipizide/metformin, respectively; the between-group difference was $0.06 \%$ (95\% CI $0.05 \%$ to $0.16 \%)$. The proportion of patients reporting $\geq 1$ hypoglycemic event over 52 weeks was low in the saxagliptin/metformin group (3.0\%), and was significantly lower compared with the glipizide/metformin group (36.3\%) (difference versus glipizide/metformin $-33.2 \%$ (95\% CI, $-38.1 \%$ to $-28.5 \% ; P<0.0001)$. Treatment with saxagliptin was associated with an adjusted mean change in body weight from baseline of $-1.1 \mathrm{~kg}$ with saxagliptin and $+1.1 \mathrm{~kg}$, with glipizide, respectively; the between-group difference was $-2.2 \mathrm{~kg}(95 \% \mathrm{CI},-2.7$ to $-1.7 ; P<0.0001)$. There was a small rise per week in $\mathrm{HbA}_{1 \mathrm{c}}$ during weeks 24-52 in both treatment groups (mean changes per week $0.001 \%$ for saxagliptin and $0.004 \%$ for glipizide). The rise per week was statistically significantly smaller with saxagliptin versus glipizide $(-0.002 \%$ difference, $95 \% \mathrm{CI},-0.0046 \%$ to $-0.0001 \% ; P=0.04)$ indicating a more sustained effect on glycemic control beyond week 24 . There were small and generally similar increases from baseline in both treatment groups in mean values for fasting insulin and fasting C-peptide. Numerical reductions in fasting proinsulin (mean difference versus glipizide/metformin $-5.5 \pm 1.67)$ and numerically smaller increases in fasting glucagon (mean difference versus glipizide/metformin $-4.9 \pm 1.88$ ) were demonstrated for saxagliptin versus glipizide. Patients treated with glipizide/metformin had a greater mean increase in HOMA-2 $\beta(+21.7 \pm 2.56)$ versus saxagliptin/metformin $(+7.4 \pm 2.54)$.

\section{Safety and tolerability}

Generally, saxagliptin has been reported to be well tolerated in clinical studies. The most common adverse events reported in patients receiving combination therapy and occurring more commonly than with metformin alone included headache $(7.5 \%$ versus $5.2 \%)$, nasopharyngitis $(6.9 \%$ versus
$4.0 \%$ ), upper respiratory tract infection, and urinary tract infection. ${ }^{25}$

Coadministration of strong cytochrome P 450 isoenzyme 3 A4/5 inhibitors (eg, ketoconazole) significantly increases saxagliptin concentrations, necessitating dose limitations to $2.5 \mathrm{mg} / 1000 \mathrm{mg}$ once daily. Lower doses of concomitantly administered sulfonylureas may be needed to reduce the risk for saxagliptin-related hypoglycemia.

Metformin-related adverse events include diarrhea and nausea/vomiting; because of the metformin-related risk for lactic acidosis, patients should be warned against excessive alcohol intake. Treatment with saxagliptin/metformin is not recommended in hepatic impairment and contraindicated in renal impairment. Renal function should be monitored before initiation of therapy and at least annually thereafter; more frequent assessments are recommended for patients at risk of renal impairment, such as the elderly. Treatment should be temporarily discontinued in patients undergoing radiologic studies with intravascularly administered iodinated contrast materials, and those undergoing surgical procedures associated with restricted intake of food and fluids.

\section{Hypoglycemia}

Hypoglycemia was reported in $3.4 \%$ of treatment-naive patients receiving saxagliptin $5 \mathrm{mg} /$ metformin combination therapy compared with $4.0 \%$ of those receiving metformin alone. Among treatment-experienced patients, the incidence of reported hypoglycemia for saxagliptin $2.5 \mathrm{mg}$ and saxagliptin $5 \mathrm{mg}$ with metformin was $7.8 \%$ and $5.8 \%$, respectively, compared with $5.0 \%$ for those receiving metformin monotherapy.

Compared to the sulfonylureas, saxagliptin gave a low incidence of hypoglycemia, as reported by Goke et al. ${ }^{24}$ Three percent of patients in the saxagliptin/metformin group and $36.3 \%$ of patients in the glipizide/metformin group experienced hypoglycemic events over the 52-week treatment period. Most hypoglycemic events were mild in intensity; $0.2 \%$ of patients in the saxagliptin/metformin group and $14.4 \%$ of patients in the glipizide/metformin group had hypoglycemic events that were moderate in intensity. No patients in the saxagliptin/metformin group and $1.6 \%$ of patients in the glipizide/metformin group had hypoglycemic events that were severe. No patients in the saxagliptin/metformin group and $0.9 \%$ of patients in the glipizide/metformin group experienced a mild hypoglycemic adverse event requiring medical assistance.

\section{Patient perspectives}

In November 2010, the US Food and Drug Administration (FDA) approved the first and only once-daily combination 
tablet featuring saxagliptin and extended-release (XR) metformin $\mathrm{HCl}$ to improve glycemic control in adults with type 2 diabetes mellitus. Saxagliptin/metformin $\mathrm{XR}$ is available in $5 \mathrm{mg} / 500 \mathrm{mg}, 5 \mathrm{mg} / 1000 \mathrm{mg}$, and $2.5 \mathrm{mg} / 1000 \mathrm{mg}$ strengths. The starting dose should be individualized based on the patient's current regimen and administered with the evening meal, with gradual dose titration to decrease the risk for metformin-related gastrointestinal events (maximum dose, $5 \mathrm{mg} / 2000 \mathrm{mg}$ ). This prescription provides good acceptability for patients with T2DM, who are commonly treated with a large number of drugs. This fixed dose combination also allows physicians to increase the antidiabetic therapy in patients not well controlled by metformin alone without increasing the number of pills taken by the patients, improving patient compliance. The combination of saxagliptin/metformin proved to be safer than combinations of sulfonylureas/metformin with respect to hypoglycemic events. ${ }^{24}$ This aspect is very important: hypoglycemia can be very dangerous in patients with coronary disease because of the risk of triggering a heart attack, and in older people because of the risk of falls. Also, the saxagliptin/metformin combination proved to be neutral or even positive with respect to body weight gain, and this is another advantage of this combination. ${ }^{24}$

\section{Conclusion and place in therapy}

The studies reported above showed that the combination of saxagliptin/metformin was well tolerated and produced sustained glycemic control for up to 76 weeks, with greater improvements in glycemic parameters when compared with either drug alone. ${ }^{20}$ These results are generally similar to those obtained with the other two DPP-4 inhibitors, sitagliptin $^{26,27}$ and vildagliptin. ${ }^{28}$ At 1 year, the least squares reduction from baseline results of $\mathrm{HbA}_{1 \mathrm{c}}$ was greater for sitagliptin/metformin 100/2000 $\mathrm{mg}(-1.9 \%)$ than for metformin $2000 \mathrm{mg}$ alone $(-1.6 \%) .{ }^{26}$ At 2 years, the initial combination reduction $(-1.7 \%)$ remained greater than that for metformin alone $(-1.3 \%)$. Other glycemic measures were consistent with the $\mathrm{HbA}_{1 \mathrm{c}}$ results. ${ }^{27}$ For vildagliptin, there was a 24 week study which compared vildagliptin combined with high-dose metformin combination therapy (50/1000 mg twice daily), vildagliptin combined with low-dose metformin combination therapy (50/500 mg twice daily), vildagliptin monotherapy (50 mg twice daily) and high-dose metformin monotherapy (1000 mg twice daily) ${ }^{28}$ From comparable baseline values $(8.6 \%-8.7 \%), \mathrm{HbA}_{1 \mathrm{c}}$ decreased in all four treatment groups, to the greatest extent with vildagliptin/ metformin 50/1000 mg twice daily. Mean $\mathrm{HbA}_{1 \mathrm{c}}$ change from baseline was: $-1.8 \% \pm 0.06 \%$ with vildagliptin/metformin $50 / 1000 \mathrm{mg}$ twice daily; $-1.6 \% \pm 0.06 \%$ with vildagliptin/ metformin $50 / 500 \mathrm{mg}$ twice daily; $-1.1 \% \pm 0.06 \%$ with vildagliptin monotherapy (50 mg twice daily); and $-1.4 \% \pm 0.06 \%$ with high-dose metformin monotherapy (1000 mg twice daily). The between-group difference was superior with vildagliptin/metformin 50/1000 mg twice daily combination therapy ( $P<0.001$ versus both monotherapies) and vildagliptin/metformin 50/500 $\mathrm{mg}$ twice daily combination therapy $(P<0.001$ and $P=0.004$, versus vildagliptin and metformin monotherapies, respectively). There was no incidence of hypoglycemia or severe hypoglycemia with either combination therapy, and neither was associated with weight gain. All treatments were well tolerated and displayed a comparable incidence of adverse events overall. Our group ${ }^{29}$ conducted a study on sitagliptin, where we compared sitagliptin/pioglitazone 100/30 mg once a day and metformin/pioglitazone 850/15 mg twice a day. After 12 months of treatment we showed that the addition of either sitagliptin or metformin to pioglitazone gave an improvement in $\mathrm{HbA}_{1 \mathrm{c}}$, FPG, and PPG; but metformin led also to a decrease in body weight and to a faster and better improvement of insulin resistance and inflammatory state parameters, even if sitagliptin gave a better protection of beta-cell function. ${ }^{29}$ We have also conducted a study on vildagliptin comparing either pioglitazone $30 \mathrm{mg}$ once a day plus vildagliptin $50 \mathrm{mg}$ twice a day or glimepiride $2 \mathrm{mg} 3$ times a day plus vildagliptin $50 \mathrm{mg}$ twice a day. We observed that, after 12 months, the pioglitazone/vildagliptin combination was more effective in preserving beta-cell function, and in reducing insulin resistance and inflammatory state parameters than vildagliptin/glimepiride. ${ }^{30}$ The positive effect on insulin resistance is very important given that the main mechanism of T2DM is insulin resistance.

When directly compared to other DPP-4 inhibitors such as sitagliptin, saxagliptin showed its non-inferiority when added to metformin therapy in lowering $\mathrm{HbA}_{1 \mathrm{c}}$. Saxagliptin was generally well tolerated in patients with T2DM whose glycemia was inadequately controlled by metformin alone. ${ }^{19}$ Saxagliptin proved also its non-inferiority compared to sulfonylureas in the study conducted by Goke et al where saxagliptin/metformin combination was well tolerated, provided a sustained $\mathrm{HbA}_{1 \mathrm{c}}$ reduction over 52 weeks, reduced body weight and a significantly lower risk of hypoglycemia. ${ }^{24}$ Furthermore, patients treated with glipizide plus metformin had a greater mean increase in HOMA-2 $\beta$, proving once again the protective effect of DPP-4 inhibitors, and in particular saxagliptin, on $\beta$-cell. ${ }^{24}$ 
Clinical practice recommendations for the treatment of T2DM advocate lifestyle interventions (dietary modification, increased exercise, weight loss) together with starting metformin treatment at the time that the T2DM is diagnosed. ${ }^{1}$ Once metformin fails to maintain glycemic control another antidiabetic drug should be added. In this setting, DPP-4 inhibitors should be the logical choice because of their comparable effects on $\mathrm{HbA}_{1 \mathrm{c}}$ compared to the addition of a sulfonylurea ${ }^{31,32}$ or glitazone, ${ }^{33,34}$ and because of their positive effects on beta cell function and their neutral effects on body weight. DPP-4 inhibitors are particularly indicated in young patients, with a long life expectancy, because of the protective effect on $\beta$-cell function. While sulfonylureas increase HOMA-2 $\beta$ and proinsulin, ${ }^{24}$ DPP-4 inhibitors reduce them, granting a longer survival of $\beta$-cells. ${ }^{29}$ DPP-4 inhibitors also reduce insulin resistance, decreasing HOMA-IR, ${ }^{29,30}$ and they also prevent the risk of hypoglycemia posed by sulfonylureas. This makes these drugs safer in elderly patients. ${ }^{35}$

\section{In summary}

- When diet and exercise are not enough to produce adequate glycemic control, metformin should be added

- When diet, exercise, and metformin are not enough, a combination therapy should be started. DPP-4 inhibitors could be a good choice

- DPP-4 inhibitors, and in particular saxagliptin, showed their non-inferiority compared to sulfonylureas in improving $\mathrm{HbA}_{1 \mathrm{c}}$

- DPP-4 inhibitors, in particular saxagliptin, gave a lower incidence of hypoglycemic events compared to sulfonylureas

- The combination of saxagliptin/metformin proved to have a positive effect on body weight.

\section{Disclosure}

The authors certify that they have no affiliation with, or financial involvement in, any organization or entity with a direct financial interest in the subject matter or materials discussed in the manuscript.

\section{References}

1. American Diabetes Association. Summary of revisions to the 2011 clinical practice recommendations. Diabetes Care. 2011;34(Suppl 1):S3.

2. Nicolucci A, Rossi MC. Incretin-based therapies: a new potential treatment approach to overcome clinical inertia in type 2 diabetes. Acta Biomed. 2008;79(3):184-191.

3. Rodbard HW, Jellinger PS, Davidson JA, et al. Statement by an American Association of Clinical Endocrinologists/American College of Endocrinology Consensus Panel on type 2 diabetes mellitus: an algorithm for glycemic control. Endocr Pract. 2009;15(6):540-559.
4. Barnett AH. Redefining the role of thiazolidinediones in the management of type 2 diabetes. Vasc Health Risk Manage. 2009;5(1):141-151.

5. Drucker DJ. Biological actions and therapeutic potential of the glucagonlike peptides. Gastroenterology. 2002;122(2):531-544.

6. Holst JJ, Gromada J. Role of incretin hormones in the regulation of insulin secretion in diabetic and nondiabetic humans. Am J Physiol Endocrinol Metab. 2004;287(2):E199-E206.

7. Drucker DJ, Nauck MA. The incretin system: glucagonlike peptide-1 receptor agonists and dipeptidyl peptidase-4 inhibitors in type 2 diabetes. Lancet. 2006;368(9548):1696-1705.

8. Deacon CF, Johnsen AH, Holst JJ. Degradation of glucagon-like peptide-1 by human plasma in vitro yields an $\mathrm{N}$-terminally truncated peptide that is a major endogenous metabolite in vivo. J Clin Endocrinol Metab. 1995;80(3):952-957.

9. Triplitt CL. New technologies and therapies in the management of diabetes. Am J Manag Care. 2007;13 (Suppl 2):547-554.

10. Baggio LL, Drucker DJ. Biology of incretins: GLP-1 and GIP. Gastroenterology. 2007;132(6):2131-2157.

11. Drucker DJ. The biology of incretin hormones. Cell Metab. 2006;3(3): 153-165.

12. Flatt PR, Bailey CJ, Green BD. Dipeptidyl peptidase IV (DPP IV) and related molecules in type 2 diabetes. Front Biosci. 2008;13: 3648-3660.

13. Drucker DJ. The role of gut hormones in glucose homeostasis. J Clin Invest. 2007;117(1):24-32.

14. Triplitt C, McGill JB, Porte D Jr, Conner CS. The changing landscape of type 2 diabetes: the role of incretin-based therapies in managed care outcomes. J Manag Care Pharm. 2007;13(9 Suppl C):S2-S16.

15. Onglyza [package insert]. Princeton, NJ/Wilmington, DE: Bristol-Myers Squibb Company/AstraZeneca Pharmaceuticals, February 2011.

16. Dickersin K, Scherer R, Lefebvre C. Identifying relevant studies for systematic reviews. BMJ. 1994;309(6964):1286-1291.

17. Jadad AR, Moore RA, Carroll D, et al. Assessing the quality of randomized controlled trials: is blinding necessary? Control Clin Trials. 1996;17(1):1-12.

18. Augeri DJ, Robl JA, Betebenner DA, et al. Discovery and preclinical profile of saxagliptin (BMS-477118): a highly potent, long-acting, orally active dipeptidyl peptidase IV inhibitor for the treatment of type 2 diabetes. J Med Chem. 2005;48(15):5025-5037.

19. Kim YB, Kopcho LM, Kirby MS, et al. Mechanism of Gly-Pro-pNA cleavage catalyzed by dipeptidyl peptidase-IV and its inhibition by saxagliptin (BMS-477118). Arch Biochem Biophys. 2006;445(1): 9-18.

20. Pfützner A, Paz-Pacheco E, Allen E, Frederich R, Chen R; for the CV181039 Investigators. Initial combination therapy with saxagliptin and metformin provides sustained glycaemic control and is well tolerated for up to 76 weeks. Diabetes Obes Metab. 2011;13(6):567-576. doi:10.1111/j.1463-1326.2011.01385.x.

21. Jadzinsky M, Pfützner A, Paz-Pacheco E, Xu Z, Allen E, Chen R; CV181-039 Investigators. Saxagliptin given in combination with metformin as initial therapy improves glycaemic control in patients with type 2 diabetes compared with either monotherapy: a randomized controlled trial. Diabetes Obes Metab. 2009;11(6):611-622.

22. Scheen AJ, Charpentier G, Ostgren CJ, Hellqvist A, Gause-Nilsson I. Efficacy and safety of saxagliptin in combination with metformin compared with sitagliptin in combination with metformin in adult patients with type 2 diabetes mellitus. Diabetes Metab Res Rev. 2010;26(7): 540-549.

23. DeFronzo RA, Hissa MN, Garber AJ, et al. for Saxagliptin 014 Study Group. The efficacy and safety of saxagliptin when added to metformin therapy in patients with inadequately controlled type 2 diabetes with metformin alone. Diabetes Care. 2009;32(9):1649-1655.

24. Göke B, Gallwitz B, Eriksson J, Hellqvist A, Gause-Nilsson I; D1680C00001 Investigators. Saxagliptin is non-inferior to glipizide in patients with type 2 diabetes mellitus inadequately controlled on metformin alone: a 52-week randomised controlled trial. Int $J$ Clin Pract. 2010;64(12):1619-1631. 
25. Rosenstock J, Sankoh S, List JF. Glucose-lowering activity of the dipeptidyl peptidase-4 inhibitor saxagliptin in drug-naive patients with type 2 diabetes. Diabetes Obes Metab. 2008;10(5):376-386.

26. Williams-Herman D, Johnson J, Teng R, et al. Efficacy and safety of initial combination therapy with sitagliptin and metformin in patients with type 2 diabetes: a 54-week study. Curr Med Res Opin. 2009;25(3): 569-583.

27. Williams-Herman D, Johnson J, Teng R, et al. Efficacy and safety of sitagliptin and metformin as initial combination therapy and as monotherapy over 2 years in patients with type 2 diabetes. Diabetes Obes Metab. 2010;12(5):442-451.

28. Bosi E, Dotta F, Jia Y, Goodman M. Vildagliptin plus metformin combination therapy provides superior glycaemic control to individual monotherapy in treatment-naive patients with type 2 diabetes mellitus. Diabetes Obes Metab. 2009;11(5):506-515.

29. Derosa G, Maffioli P, Salvadeo SA, et al. Effects of sitagliptin or metformin added to pioglitazone monotherapy in poorly controlled type 2 diabetes mellitus patients. Metabolism 2010;59(6):887-895.

30. Derosa G, Maffioli P, Ferrari I, et al. Effects of one year treatment of vildagliptin added to pioglitazone or glimepiride in poorly controlled type 2 diabetic patients. Horm Metab Res. 2010;42(9):663-669.
31. Nauck MA, Meininger G, Sheng D, Terranella L, Stein PP. Efficacy and safety of the dipeptidyl peptidase peptidase-4 inhibitor, sitagliptin, compared with the sulfonylurea, glipizide, in patients with type 2 diabetes inadequately controlled on metformin alone: a randomized, double-blind, non-inferiority trial. Diabetes Obes Metab. 2007;9(2): 194-205.

32. Ferrannini E, Fonseca V, Zinman B, et al. Fifty-two-week efficacy and safety of vildagliptin vs glimepiride in patients with type 2 diabetes mellitus inadequately controlled on metformin monotherapy. Diabetes Obes Metab. 2009;11(2):157-166.

33. Bolli G, Dotta F, Rochotte E, Cohen SE. Efficacy and tolerability of vildagliptin vs pioglitazone when added to metformin: a 24-week, randomized, double-blind study. Diabetes Obes Metab. 2008;10(1): $82-90$

34. Scott R, Loeys T, Davies MJ, Engel SS. Efficacy and safety of sitagliptin when added to ongoing metformin therapy in patients with type 2 diabetes. Diabetes Obes Metab. 2008;10(10):959-969.

35. Barzilai N, Guo H, Mahoney EM, et al. Efficacy and tolerability of sitagliptin monotherapy in elderly patients with type 2 diabetes: a randomized, double-blind, placebo-controlled trial. Curr Med Res Opin. 2011;27(5):1049-1058.

\section{Publish your work in this journal}

Diabetes, Metabolic Syndrome and Obesity: Targets and Therapy is an international, peer-reviewed open-access journal committed to the rapid publication of the latest laboratory and clinical findings in the fields of diabetes, metabolic syndrome and obesity research. Original research, review, case reports, hypothesis formation, expert opinion and commentaries are all considered for publication. The manuscript management system is completely online and includes a very quick and fair peer-review system, which is all easy to use. Visit http://www.dovepress.com/testimonials.php to read real quotes from published authors. 